\title{
O papel do jogo no ensino de radioatividade: os softwares Urânio-235 e Cidade do Átomo.
}

\section{Marcelo Leandro Eichler Fernando Junges** José Claudio Del Pino***}

Resumo: No desenvolvimento de estratégias de ensino e de aprendizagem, muitas vezes, o papel do jogo é subestimado e reconhecido apenas por suas possíveis características de motivação ou incentivo às ações educativas. Nesse artigo, apresentamse dois softwares educativos que, a partir de diferentes perspectivas, abordam o mesmo assunto presente no ensino médio, a radioatividade. Apresenta-se, também, a possibilidade de utilização da estratégia pedagógica de jogos de representação de papéis para um desses softwares. Nesse sentido, indica-se a preponderante ação do professor na condução dessa estratégia.

Palavras-chave: software educativo; jogos educacionais; radioatividade.

Abstract: [The role of the play in the radioactvity teaching: Uranium-235 and Atom City softwares]. In the development of teaching and learning strategies, the role of plays is often underestimated and just recognized for its probable characteristics of motivation or encouragement of educational actions. In this paper, we introduce two educational softwares that deal, from different approaches, with the same High School subject: radioactivity. Besides, it is also presented the possibility of employing roleplaying as a teaching strategy in the use of one of those softwares. In this sense, we point out to the importance of teacher's action on conducting such strategy.

Keywords: educational software, educational games, radioactivity.

\footnotetext{
${ }^{1}$ Licenciado em Química e Doutor em Psicologia do Desenvolvimento pela UFRGS, é professor do Instituto de Química e pesquisador da Área de Educação Química (AEQ) da UFRGS. Autor correspondente: exlerbr@yahoo.com.br

** Bacharel em Química e doutorando em Química pela UFRGS, foi bolsista de iniciação científica (CNPq) na AEQUFRGS.
} 


\section{Introdução:}

Em maio de 2005, segundo a imprensa (Romero, 2005), é lançado mais um jogo de computadores que tem a radioatividade como tema de seu enredo. O jogo S.T.A.L.K.E.R.: The Shadow of Chernobyl traz uma especulação sobre o acidente nuclear ocorrido nessa cidade da Ucrânia. Nesse jogo, os moradores de Chernobyl são aterrorizados por "um grande número de criaturas estranhas e monstruosas" que foram originadas pelas mutações ocasionadas pela radiação decorrente da explosão da usina nuclear. O jogo foi desenvolvido pela GSC Game World, uma empresa russa, sob a base da Inteligência Artificial e utiliza uma perspectiva de primeira pessoa em 3D na representação das ações do jogador.

Esse é um exemplo atual da radioatividade como metáfora para o desenvolvimento fantasioso de jogos de computador. Poderíamos fazer uma revisão e ver a persistência temporal dessa metáfora na imaginação dos produtores de jogos de computador, de filmes ou de histórias em quadrinhos (Hulk e Godzilla, por exemplo). Entretanto, o que aqui nos interessa, nessa introdução, é apresentar os gêneros de jogos de computador e seu possível aproveitamento para as atividades de ensino e de aprendizagem.

A equipe do professor sul-africano Alan Amory desenvolveu uma pesquisa sobre o uso do computador como ferramenta educacional (Amory, Naicker, Vincent e Adams, 1999) envolvendo jogos comerciais de entretenimento bastante utilizados por estudantes do ensino médio. A seguir são apresentadas algumas informações relacionadas a essa pesquisa.

Em informática, pode-se entender o jogo como um programa de computador caracterizado pela intensa interatividade e participação do usuário, que utiliza sua habilidade com os dispositivos de entrada, seu raciocínio lógico e sua imaginação para alcançar um determinado objetivo. $\mathrm{O}$ objetivo do jogo pode ser uma tarefa simples e direta, como chegar em primeiro lugar em uma corrida ou eliminar todos os adversários em lutas. O objetivo, também, pode ser mais complexo, com um emaranhado de quebracabeças e trabalhos para resgatar uma princesa ou salvar um mundo, por exemplo.

Os jogos utilizam recursos dos dispositivos de saída, como desenhos no monitor e ruídos através da placa de som, para mostrar ao jogador o estado corrente do jogo e para orientá-lo e estimulá-lo à conquista do objetivo. Nesse sentido, pode-se dizer que jogos bem elaborados possuem história intrincada, personagens marcantes e objetivos misteriosos.

Os jogos podem ser classificados em relação: ao espaço (dimensionalidade), ao gênero e à perspectiva do jogador. Quando o espaço do jogo está restrito a duas dimensões, diz-se tratar de um jogo 2D. Por outro lado, se as entidades do jogo são representadas com três coordenadas, trata-se de um jogo 3D.

Da mesma maneira que os filmes, os jogos também podem ser classificados em relação aos diferentes gêneros de seu enredo (por exemplo, guerra, policial e terror). Esses são determinados, essencialmente, pela forma como o jogador controla o jogo e, também, através da perspectiva que possui o jogador de suas ações no jogo.

Com relação à perspectiva, os jogos podem ser divididos em visão em primeira pessoa e visão em terceira pessoa. Em relação ao primeiro tipo, enquadram-se aqueles em que a imagem na tela representa exatamente a visão do personagem do jogador. Dessa maneira, o jogador quase nunca vê o personagem em si, a não ser, por exemplo, quando fica em frente a um espelho durante o jogo. Jogos com visão em terceira pessoa são aqueles em que a visão do jogador não coincide com a de seu personagem e, assim, o personagem do jogador pode ser visto. A câmera do jogo se movimenta de acordo 
com ele, mantendo-o sempre visível e no centro da tela. Por essas características, os jogos em primeira pessoa tendem a ser mais imersivos.

De acordo com as formas de controle do jogo, os jogos podem ser divididos nos seguintes gêneros: ação, aventura, estratégia, interpretação (ou RPG, role-playing games) e esporte. Desses diversos gêneros, os pesquisadores em educação costumam se concentrar em dois tipos: aventura e estratégia.

Nos jogos de aventura, o jogador deve decifrar enigmas, resolver quebra-cabeças e solucionar problemas que envolvem lógica, raciocínio e reconhecimento de padrões. O jogo é centralizado na história, e não se exige muita habilidade com os dispositivos de entrada (teclado e mouse, por exemplo). O avanço e a solução dos enigmas são presenteados com o desenvolvimento da história. O Urânio 235, que descreveremos na seção seguinte, faz parte desse gênero de jogo.

Nos jogos de estratégia, o jogador atua como comandante tático de um grupo de personagens. As ações consistem em expedir ordens de movimento (por exemplo, de ataque ou defesa) a esses personagens, buscando sobrepujar taticamente o(s) oponente(s) (que pode ser o próprio computador). Um clássico exemplo desse tipo de jogo é o SimCity .

$\mathrm{Na}$ pesquisa realizada por Amory e colaboradores com diversos jogos de computador, constatou-se que os jogos de aventura e de estratégia propiciaram aos participantes da pesquisa a aprendizagem do enredo através da visualização e da criatividade. Um dos enredos, por exemplo, tinha como tema a Alquimia (no caso, o jogo Zork Nemesis) e havia a necessidade do jogador dominar conceitos relacionados a essa temática para evoluir nas etapas do jogo. Segundo os pesquisadores, a aprendizagem ocorreu porque os jogadores foram hábeis em visualizar a causa e o efeito de suas próprias ações em todo o sistema. Notou-se, também, que foram desenvolvidas habilidades de tomada de decisão durante o jogo.

Além disso, em relação à motivação, os participantes da pesquisa indicaram que para um jogo se tornar divertido são necessários elementos de fantasia, curiosidade, novidade, complexidade e desafio.

Nas seções seguintes, apresenta-se um jogo de aventura (Urânio 235) e um software educativo que inclui uma estratégia de jogo de representação de papéis (Cidade do Átomo). Esses programas de computador têm em comum o fato, raro, de serem feitos no Brasil e envolverem temas relacionados à química, no caso, o mesmo tema, radioatividade.

\section{Urânio 235}

O Urânio 235 é um jogo de aventura em 3D e em primeira pessoa. Na época de seu lançamento, o informe publicitário dizia que esse era o primeiro jogo de aventura nacional. Por outro lado, no manual do usuário do jogo constam algumas relações entre a finalidade do jogo e seu objetivo educativo, por exemplo:

"Com a finalidade de mostrar que a ciência, principalmente a química, não é algo de outro planeta, é que foi desenvolvido este 'software'. É possível aprender química! (...) Este jogo foi feito para que os estudantes de primeiro e segundo grau adquiram uma noção de química, e aprendam alguns conceitos básicos" (p. 7).

"Este jogo tem a finalidade de tornar os conhecimentos básicos em química uma diversão, onde o jogador deve prestar atenção aos detalhes e explorar atentamente os locais por onde passar. (...) Com a utilização dos conhecimentos adquiridos durante o jogo, com espírito de aventura, raciocínio e um pouco de criatividade 
você, jogador, chegará ao final de sua missão. (...) Sua aventura começa em uma aldeia [de outro planeta; logo no começo do jogo o jogador é abduzido por um disco voador] que foi abandonada, pois no passado, uma equipe de cientistas confirmou que o Urânio presente nas rochas emitia radioatividade. Como foi utilizado de forma indevida, grande parte da população foi destruída. E agora cabe a você tornar o local habitável novamente” ( $p .10)$.

O jogo apresenta os seguintes conteúdos de química do programa do primeiro e segundo ano do ensino médio: matéria; modelos atômicos; estados físicos da matéria; misturas e separações; tabela periódica; ligação química; funções químicas; reações químicas; e, obviamente, radioatividade. Na Figura 1 se pode ver uma das telas dos diversos cenários do programa.

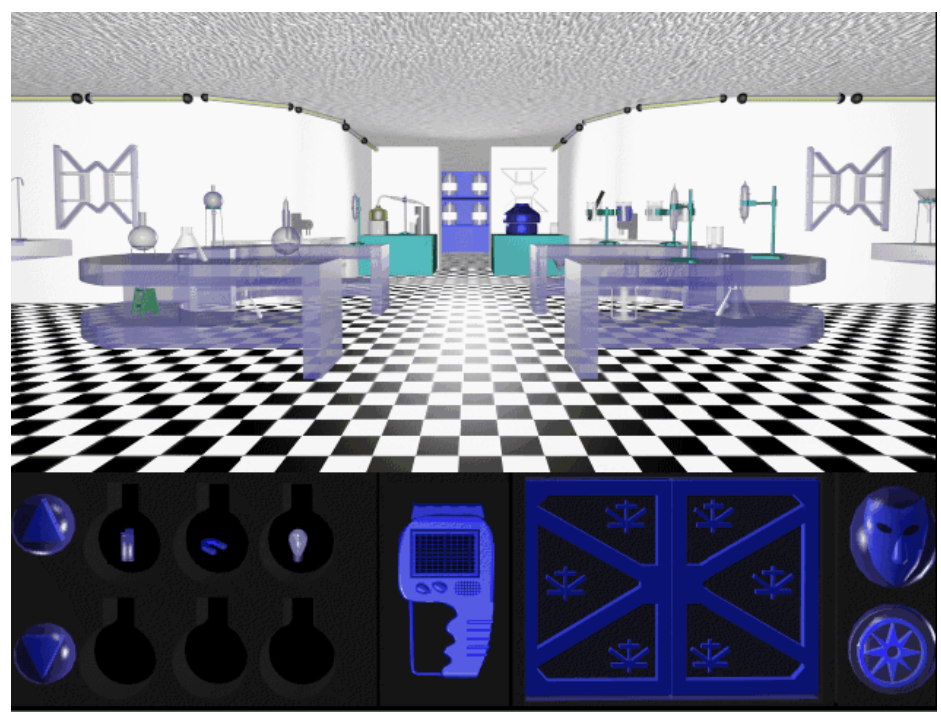

Figura 1 - Cenário que representa um laboratório, onde o jogador é desafiado a separar diferentes tipos de misturas.

Embora conheçamos esse jogo desde o seu lançamento, não chegamos a investigar se esse jogo é considerado desafiante para os usuários a que ele se destinaria, ou seja, estudantes da escola básica. Isso porque, em uma análise que fizemos do programa (Silva, Junges, Eichler e Del Pino, 1997), ele nos pareceu regular demasiadamente as interações do jogador e dificultar a passagem entre as fases do programa, ou seja, entre os cenários que compõem o roteiro do jogo. Por exemplo, é necessário consultar todos os elementos que constam em um dado cenário para passar ao outro. Ou seja, mesmo que algum jogador já conheça um ou outro dos conteúdos da química apresentado em um determinado cenário, ele deve clicar sobre os elementos e ouvir, novamente, esses conteúdos para que o programa libere para ele a oportunidade de resolver o problema relacionado a esse cenário. Uma vez que outros jogos de aventura, sem finalidades educacionais, não apresentam esse tipo de limitação na interação com o programa, supomos que esse jogo não seria desafiador para os sujeitos, podendo ser, ao contrário, considerado desinteressante.

Na metáfora utilizada para a construção do enredo do jogo, de maneira bastante criativa, há a solução de uma das grandes inquietações da humanidade: sim, existem seres extraterrestres! Além de eles existirem, dominam a tecnologia nuclear e viajam pelo cosmos para abduzir seres humanos quando se encontram em dificuldades, nesse caso, quando boa parte de sua população foi morta. Concessões imaginativas de roteiro 
à parte, os jogos contêm diversos equívocos do ponto de vista do conhecimento em química, por exemplo:

a) Quando se derrama ácido sobre um cadeado de ferro este é corroído imediatamente (desaparece no mesmo instante que é colocado o ácido). Essa situação não leva em consideração o aspecto cinético envolvido nas reações químicas. Possivelmente uma reação como essa se processaria em dezenas de minutos ou mesmo em horas ou semana, dependendo da concentração utilizada do ácido.

b) Quando se despeja o conteúdo de um vidro de base num lago ácido esse se torna neutro. Nessa situação, é o aspecto estequiométrico das reações químicas que é deixado de lado. Fazendo uso apenas de características qualitativas, não se considera que o volume de substância básica contida em vidro não seria suficiente para neutralizar a acidez de um lago.

c) No mesmo instante em que o reator é desligado, a radiação dissipa e a cidade volta a ser habitada. Talvez esse seja o maior equívoco conceitual, pois a atividade das radiações é dependente da meia-vida (tempo necessário para a atividade de uma amostra ser reduzida à metade de sua atividade inicial) dos isótopos radioativos em questão. A meia-vida do Urânio 235 é de 713 milhões de anos. A grande meia-vida dos isótopos utilizados na produção elétrica, associados ao perigo de sua liberação na natureza, é um dos fortes argumentos utilizados pelos opositores à produção de energia elétrica através da energia nuclear.

Em resumo, o programa negligencia alguns outros conteúdos da química, tais como: relações estequiométricas (principalmente, concentração das soluções), rapidez de reação e meia-vida, sendo esse um dos conceitos-chave para compreender a temática da radioatividade.

Nesse sentido, se um professor considera que um programa como o Urânio 235 pode ser utilizado como um elemento de motivação para as aulas de química, ou mesmo se percebe que pode utilizá-lo como uma fonte de informações, é necessário que chame a atenção dos alunos para esses equívocos. Podendo, inclusive utilizar tais equívocos para desenvolver juntos com os alunos uma melhor elaboração conceitual dos conteúdos incluídos no enredo do programa. E já que falamos em jogo, poder-se-ia, por exemplo, propor uma atividade para os alunos que envolvesse o jogo dos erros: eles deveriam, nesse caso, buscar evidenciar os erros conceituais ou de integração conceitual presentes no programa de computador.

\section{A importância cognitiva dos jogos.}

$\mathrm{O}$ entendimento de senso comum costuma definir o jogo de forma oposta ao trabalho ou ao estudo (Rieber, Smith e Noah, 1998). Essa idéia pode ser abonada através de dicionários, onde se pode encontrar as seguintes definições de jogo: 1. Brincadeira, divertimento, folguedo. 2. Passatempo, em que de ordinário se arrisca dinheiro, ou outra coisa. 3. Divertimento ou exercício de crianças, em que elas fazem prova da sua habilidade, destreza ou astúcia.

Por outro lado, desde a psicologia, a importância do jogo na representação do conhecimento e para o desenvolvimento cognitivo foi apontado por Jean Piaget (1945/1975). Nesse sentido, o jogo é entendido como um grande exercício para a aquisição do pensamento abstrato, sendo o instrumento através do qual o sujeito apropria-se do mundo e pode transformá-lo (Paula, 1996).

Entretanto, neste artigo procuramos mostrar o papel do jogo na aprendizagem através de algumas compreensões de Lloyd Rieber, um importante desenvolvedor de softwares educativos para o ensino de ciências. 
Em relação à associação do jogo com o computador, costuma-se, também, estereotipar os jogadores de vídeo game, tomando-os, por exemplo, por "cabeças-devento" (Rieber, Smith e Noah, 1998). Entretanto, como indicam esses autores, tal estereótipo seria rapidamente apagado se se solicitasse que os jogadores descrevessem as regras de um certo jogo e as relações entre os objetos que aparecem na tela e suas funcionalidades nesse jogo. Dessa forma, seria possível reconhecer que essa criança (ou adolescente) pode ser um perito no complexo "mundo virtual" e facilmente poderia passar no mais forte teste ligado ao "conteúdo" do jogo, embora os adultos, em geral, valorizem pouco esse conhecimento.

Rieber (1996) indica que existem importantes relações psicológicas (motivação e entusiasmo, por exemplo) e culturais com o jogo (ritos e desenvolvimento moral, p.e.). Entretanto, lamenta que o valor dos jogos como ferramenta ou estratégia instrucionais tem sido ambivalente. Nesse sentido, exemplifica que o uso de jogos e simulações é adotado em certos ambientes educacionais, como os ambientes de treinamento corporativos ou militares. Por outro lado, na escola básica os jogos teriam grande aceitação nas séries iniciais, com um decréscimo de interesse entre professores e pais nos anos finais do ensino fundamental e em todo o secundário.

Dessa maneira, conforme Rieber (1996), por um lado, entende-se que em outras épocas o jogo fora visto como uma distração prejudicial para os estudos da criança. Por outro lado, em nossa época o jogo deveria ser entendido em um sentido produtivo e natural do engajamento de crianças e de adolescentes em atividades de solução de problemas e de construção de conhecimentos. É nesse sentido que se quer ressaltar a importância cognitiva dos jogos e, portanto, conforme indicam Rieber e Matzko (2001), muitas vezes, os melhores projetos didáticos evocam a experiência do jogo, pois provocam a tendência natural da pessoa improvisar com certos problemas até eles serem resolvidos.

Em psicologia do desenvolvimento humano é possível constatar que o jogo e a imitação são estratégias naturais de aprendizagem (Piaget, 1975). Nesse sentido, embora as estratégias de imitação e de jogo sejam geralmente consideradas como estratégias para crianças muito jovens (por exemplo, Piaget as discute mais em relação aos estágios sensório-motor e pré-operatório do desenvolvimento), elas continuam importantes para as estratégias de assimilação e acomodação ao curso da vida.

Verifica-se que mesmo o mais simples dos jogos contém um conjunto complexo de propriedades. Nesse sentido, jogar um jogo de forma bem sucedida pode requerer pensamento crítico e habilidades de resolução de problemas.

Uma vez que os adultos tendem a subestimar a complexidade dos jogos das crianças, Rieber (2001) propõe a expressão "jogo sério" para retificar os modos mais típicos dos adultos de usar a palavra jogo. Essa expressão parece contraditória, pois o jogo parece algo divertido e mesmo frívolo, mas nunca nada sério. Dessa forma, ele usa a expressão "jogo sério" para chamar atenção ao fato que está interessado em um tipo de jogo que tem determinado propósito, que é igualmente negociado entre o aprendiz e o professor. Conforme esse autor indica, uma maneira simples de entender o jogo sério em educação seria através do rótulo "experimentar primeiro, explicar depois". Um professor que seguisse esse rótulo focalizaria as maneiras de engajar os aprendizes em alguma experiência significativa tão cedo quanto possível e, então, utilizaria essa experiência como uma âncora para a instrução seguinte. Por exemplo, uma explicação da física subjacente ao basquete seria mais bem compreendida após se ter muitas oportunidades de testemunhar, jogar e estudar o evento. Ou seja, a forma forte do argumento de Rieber é que o jogo pode ter um propósito cognitivo ou educativo. 
É nesse sentido, que em outros trabalhos esse autor (Rieber, Smith e Noah, 1998) propõe o jogo como uma estratégia adequada para as situações que requeiram o engajamento de crianças ou de adultos em um pensamento criativo de alta ordem e que exijam um intenso comprometimento e envolvimento pessoal. Além disso, reconhece a utilidade dos jogos, também, como uma forma de prover estrutura e organização para domínios complexos ou novos.

Finalmente, Rieber, Smith e Noah (1998) propõem que as tendências atuais no projeto de tecnologias computacionais interativas oferecem uma oportunidade ímpar para suportar o jogo sério para a aprendizagem.

\section{Os jogos de representação de papéis.}

$\mathrm{Na}$ introdução, apontamos que o jogo de representação de papéis é um dos gêneros de jogo de que dispõem os professores para a escolha de suas estratégias de aprendizagem com o uso de computadores. Nessa secção, abordaremos a utilização pedagógica dessa estratégia e a seguir, em uma próxima secção, apresentaremos um software que incorpora em sua atividade de conclusão uma atividade de representação de papéis.

A estratégia pedagógica de representação de papéis é um tema bastante disseminado na literatura em inglês (Blatner, 2002; Bonnet, 2000, Cronin-Jones, 2000; Duveen e Solomon, 1994; Jackson e Walters, 2000; Maier, 1991; Trumbore, 1974; Whisnant, 1992), entretanto para esse tema se encontra pouco material em português (basta procurar, por exemplo, as expressões "jogo de representação de papéis" e "educação" no Google e verificar a pequena quantidade de remissivas que serão encontradas).

Segundo Blatner (2002), a representação de papéis é um método para a exploração de assuntos em situações sociais complexas e polêmicas. Dessa forma, ela pode ser utilizada para o treinamento profissional (por exemplo, a formação de pilotos da aviação civil ou treinamento de militares em jogos de guerra) ou em salas de aula para a compreensão de literatura, história ou ciência.

Entretanto, Maier (1991) adverte que a técnica da representação de papéis é, muitas vezes, mal utilizada porque é mal compreendida, ou vice-versa. Ele aponta que essa é uma técnica valiosa para:

a) a aquisição de habilidades (relacionadas ao desenvolvimento de competências comportamentais, tais como a comunicação);

b) auxiliar a compreensão conceitual; e/ou

c) enriquecer a experiência afetuosa entre os aprendentes.

Nesse sentido, Maier adverte que o professor deve procurar perceber qual é o seu foco principal com a utilização dessa estratégia. Pois, justamente, é em relação ao foco escolhido que a atividade deve ser desenvolvida.

Blatner (2002), também, chama a atenção da aprendizagem de habilidades através da representação de papéis, que envolveriam resolução de problema, comunicação e autoconsciência. Conforme esse autor, tais habilidades seriam necessárias para um pensamento flexível, auto-expressivo, recursivo (feedback) e de tomada de risco, que são, justamente, os processos de pensamento mais próximos às demandas das soluções de problemas complexos, como os ambientais, por exemplo. Nesse sentido, que Blatner subscreve a importância de alinhar a representação de papéis com as simulações.

Em relação à aprendizagem conceitual, o artigo de Cronin-Jones (2000) é de grande utilidade. A seguir, abordamos algumas recomendações dessa autora para 0 planejamento e desenvolvimento de atividades de representação de papéis. 
Inicialmente, essa autora pontua que os professores, quando projetam atividades de representação de papéis, podem enfocar eventos recentes e escolher assuntos que possam interessar aos estudantes, tais como o aquecimento global, a poluição das águas, a engenharia genética, o desmatamento e o crescimento populacional. Dessa forma, artigos recentes de jornais e revistas podem ser uma excelente fonte de idéias para essas atividades.

Porém, é necessário diferenciar as atividades por representação de papéis dos simples debates com finalidades educacionais. Embora, tais estratégias sejam semelhantes, pois ambas priorizam um problema que ainda não foi resolvido pela sociedade e podem auxiliar os estudantes a praticar a comunicação verbal e a busca de informações, elas se diferenciam na amplitude dos vieses que são postos em discussão.

Os debates envolvem apenas dois grupos de estudantes, os que possuem opinião favorável ao tema em debate e aqueles que tem opinião contrária. Por exemplo, fazer um debate sobre energia nuclear, consistiria em perguntar aos alunos se eles são contra ou a favor a produção de energia nuclear e escrutinar seus motivos. Pode-se notar que essa abordagem é polarizada e pode favorecer pensamentos de tipo dualístico, no qual se acreditaria que para os assuntos em debate haveria apenas duas posições, uma sendo considerada certa e a outra errada.

Dessa maneira, diferente dos debates, as atividades de representação de papéis envolvem no mínimo quatro grupos de estudantes, com diferentes pontos de vista e perspectivas. Os estudantes que participam em atividades de representação de papéis percebem que, por exemplo, os assuntos relacionados com a ciência e a tecnologia são, em geral, complexos e que para os quais não existem soluções simples.

Escolhido a temática para a atividade, o próximo passo para os professores é desenvolver um cenário, que pode conter uma descrição real ou hipotética do assunto a ser abordado, do problema a ser resolvido ou evitado. $\mathrm{O}$ cenário deve claramente descrever a temática em questão e identificar os personagens que estão envolvidos na representação de papéis. Os personagens podem ser poucos, como quatro ou cinco, reunindo grupos de estudantes, ou muitos, como um por estudantes. O cenário pode envolver, por exemplo, a discussão sobre a produção de energia elétrica através da utilização da energia nuclear, como descreveremos na próxima secção.

O próximo ponto é desenvolver orientações que sumarizem os pontos-chave e os argumentos que poderão ser apresentados pelos personagens. Essa orientação pode incluir as seguintes questões:

1) Sua posição é favorável ou contrária ao assunto?

2) Que argumentos suportam essas sua posição?

3) Que outros indivíduos, grupos ou organizações você acha que concordam com sua posição?

4) Que outros indivíduos, grupos ou organizações você acha que discordam de sua posição?

5) Quais são alguns argumentos contrários a sua posição?

6) Como você poderia responder a esses argumentos?

Os professores devem, ainda, escolher um formato para a apresentação dos posicionamentos dos personagens sobre o tema em discussão. As atividades de representação de papéis podem ser desenvolvidas através dos seguintes formatos:

a) um fórum aberto com um moderador, onde qualquer um que queira falar pode fazê-lo por determinado tempo, quando indicado pelo moderador;

b) uma discussão em mesa redonda, com um determinado tempo de fala para cada um dos oradores, seguido da confrontação entre posições antagônicas; e 
c) uma sala forense, com um juiz e um júri externo, onde as apresentações devem ser feitas com um tempo determinado para os argumentos de cada posição, algum tempo para exames e refutações e, por fim, um tempo para os argumentos de encerramento.

Por fim, as regras do jogo devem, também, ser acordadas entre alunos e professor de forma a descrever os procedimentos de votação das propostas que visem a resolver o assunto. Os votos podem ser individuais, por delegação ou feitos pelo júri externo. É necessário, ainda, tomar algumas decisões sobre a apuração desses votos para decidir a resolução a ser tomada pelos participantes do jogo. A resolução pode depender de maioria simples ou de uma maioria significativa, como por exemplo, de dois-terços ou dos votos.

Exemplos do desenvolvimento dessa estratégia podem ser encontrados para diferentes temáticas em discussão, tais como: criacionismo versus especiação (isto é, teoria evolucionária de Darwin) (Duveen e Solomon, 1994), química analítica (Jackson e Walters, 2000), poluição atmosférica (Trumbore, 1974), poluição de cursos d'água (Whisnant, 1992) e reciclagem de papel (Bonnet, 2000).

Em relação a essa última temática, Bonnet (2000) exemplifica os conflitos que podem ser mobilizados durante a atividade de representação de papéis, tais como:

- os valores ambientais como opostos aos valores econômicos (incluindo, por exemplo, a manutenção do trabalho e o manejo de florestas);

- os valores ambientais como opostos aos valores financeiros (por exemplo, o papel reciclado é mais caro).

Algumas outras recomendações são encontradas na literatura. Jackson e Walters (2000) ponderam que a representação de papéis é uma estratégia que envolve a utilização de personalidades deliberadamente exageradas ou de estereótipos culturais. Dessa forma, os personagens da atividade são pensados em relação aos conflitos que podem ser mobilizados nas discussões. Em relação à poluição atmosférica, por exemplo, Trumbore (1974) projetou uma atividade que possui os seguintes grupos de personagens: (a) meteorologistas; (b) médicos; (c) defensores públicos; (d) dirigentes da companhia de energia; (e) dirigentes de companhias petroquímicas (poluidoras); e (f) espectadores ou o "público em geral".

Finalmente, é necessário estabelecer um tempo para o desenvolvimento dessa atividade. Isso depende de diversos fatores, talvez sendo preponderante o nível de profundidade que se deseja para os argumentos que serão utilizados na discussão. Por exemplo, as atividades elaboradas por Trumbore foram dirigidas ao ensino superior, portanto foram realizadas em cerca de cinco semanas. Período que compreendeu a apresentação da estratégia, a discussão e estabelecimento das regras do jogo, a consulta bibliográfica, as entrevista com os consultores, a elaboração dos dossiês, os debates, a proposição das decisões apropriadas a serem tomadas em relação ao problema em debate e a votação das proposições.

Cidade do Átomo

Cidade do Átomo é um software educativo que pretende colaborar para a abordagem escolar do tema radioatividade. O software utiliza uma abordagem de resolução de problemas, relacionado à proteção radiológica, e permite desenvolver uma estratégia pedagógica de jogo de papéis para discussões sobre a produção de energia elétrica através do uso da energia nuclear.

O software Cidade do Átomo se encontra em fase final de implementação . Esse software faz parte de um projeto que visa a produção de materiais didáticos computacionais para o ensino de ciências (Eichler, Gonçalves, Silva, Junges e Del Pino, 
2003) que utiliza os meios de produção de energia elétrica e seus impactos ambientais e sociais como tema gerador. As características desse software são similares aquelas de Carbópolis, o primeiro produto deste projeto (Eichler e Del Pino, 2000). Além da temática, o que Cidade do Átomo apresenta de diferente é a incorporação de uma estratégia de jogo de representação de papéis. O cenário previsto para essa atividade pode ser visto na Figura 2.

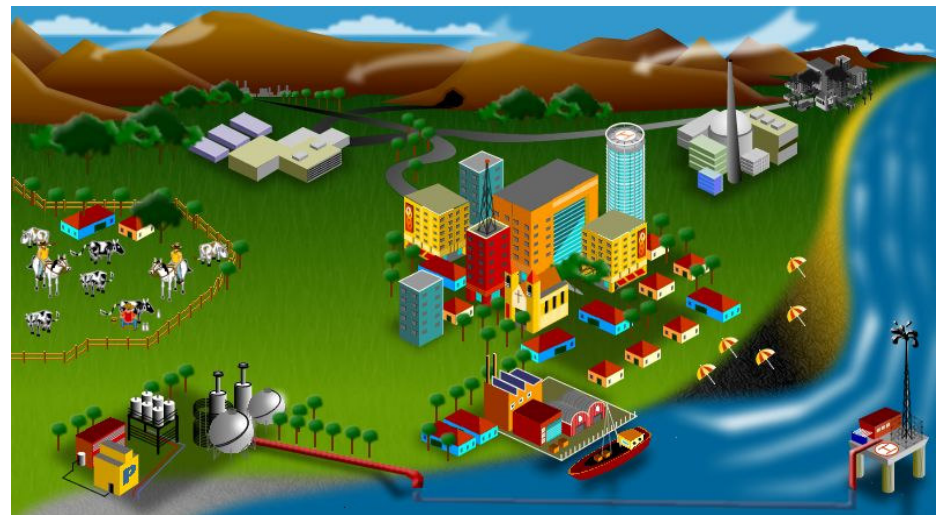

Figura 2 - Cenário da Cidade do Átomo, em que aborda o possível impacto ambiente da produção de energia nuclear.

O problema apresentado em Cidade do Átomo envolve um projeto de expansão da usina nuclear. O usuário do software, dessa forma, depois de utilizar o programa deve se posicionar sobre tal projeto de expansão. A utilização do software envolve, resumidamente, as seguintes tarefas:

1) inspeção de uma usina nuclear, para verificar se as doses de radiação recebidas pelos trabalhadores da usina se encontram dentro dos valores seguros, que não afetam a saúde, conforme recomendações de proteção radiológica;

2) coleta e análise de amostras de água e de solo, visando a verificar se a radiação de fundo na região de Cidade do Átomo se encontra em valores aceitáveis e condizentes com outras regiões do país e do mundo (dados encontrados no hipertexto que acompanha o software); e

3) coletar e debater os depoimentos da população de Cidade do Átomo, para verificar como os habitantes da cidade de fato se posicionam sobre a polêmica da produção de energia nuclear.

No cumprimento de suas tarefas, o usuário tem a sua disposição, entre outras ferramentas: a) uma Biblioteca, que contém uma série de textos sobre os conceitos básicos de radiação, de radioatividade e de energia nuclear; b) uma hemeroteca, que está junto à Biblioteca, e contém a cópia de notícias e reportagens encontradas em diversos jornais e revistas nacionais nos últimos dez anos; e c) um bloco de notas, onde é possível escrever e armazenar as conclusões parciais sobre os assuntos que estão sendo estudados.

Depois de concluir as tarefas indicadas, o usuário deve preencher um Laudo de Inspeção de Usina Nuclear (LIUN) e, a seguir, escrever um texto em que apóie ou desaprove o projeto de ampliação da usina nuclear, justificando sua opinião. É esse texto que, por exemplo, pode servir de apoio para a atividade de representação de papéis.

Além das informações textuais presentes na Biblioteca e dos valores de radiação obtidos com a inspeção da usina e com a coleta de amostras, é oferecida ao usuário uma 
atividade em que ele pode verificar os depoimentos de diversos "moradores" de Cidade do Átomo. Esses depoimentos podem ser obtidos através da navegação sobre a ilustração da Praça Central de Cidade do Átomo, conforme Figura 3.

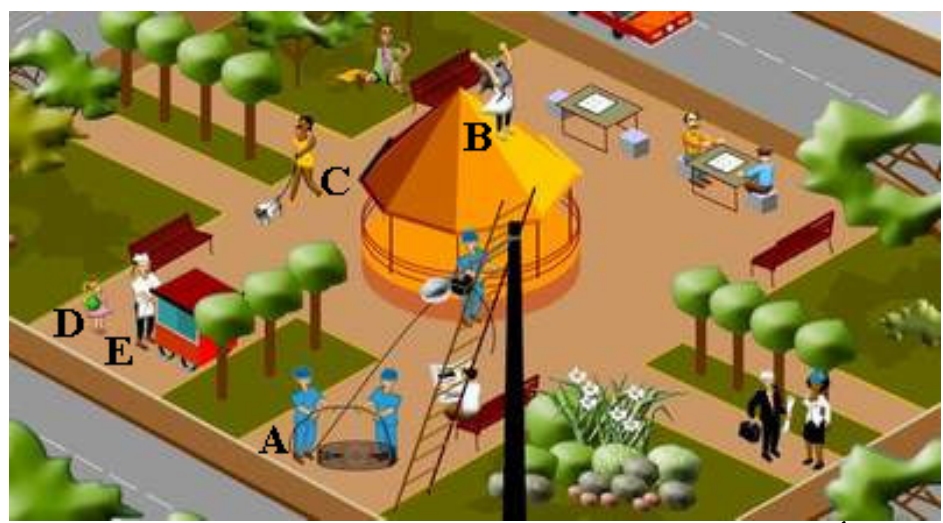

Figura 3 - Ilustração da Praça Central de Cidade do Átomo.

Os depoimentos presentes nessa atividade são contraditórios, uns em relação ao outros. Isso para mostrar as diferentes abordagens que podem ser dadas a um tema polêmico como a produção de energia nuclear. No total existem 11 depoimentos de personagens. Esses depoimentos foram extraídos de um fórum escrito promovido pelo ReporterTerra sobre o tema produção de energia termonuclear, à época de lançamento da Usina Angra 2 (Eichler e Del Pino, 2002). Na Figura 3, as letras indicam alguns depoimentos que destacamos:

A) "Não se pode desenvolver um país sem energia e a que se tem atualmente de forma mais viável é a energia nuclear. As hidroelétricas e a queima de carvão causam um tremendo impacto ambiental".

B) "O homem, com suas idéias avançadas, aos poucos está cavando o seu próprio buraco".

C) "A tecnologia que tem em nossas usinas nucleares deixa até paises de primeiro mundo de boca aberta... Sou a favor, tem riscos, mas o que hoje em dia não é um risco?".

D) "Acho que esse tipo lixo atômico é orrivel tambem para o meio ambiente porque no futuro se ouver algum tipo de vasamento pode sim e com toda sertesa prejudicar não só o meio ambiente mas a todos os seres vivos" [no fórum do ReporterTerra a escrita estava assim, pois o participante era uma garotinha, dessa forma, decidimos por manter a escrita as suas incorreções apresentadas].

E) "Acho que não deveria existir energia através de usinas nucleares porque é como se fosse uma bomba pronta para explodir. Só não explode porque é controlada, mas se houver algum vazamento como é que fica?".

Esses depoimentos podem ser utilizados pelo usuário para subsidiar a escrita de seu posicionamento sobre a energia nuclear, conforme consta na última pergunta do laudo de inspeção. Além disso, também, podem subsidiar as atividades de representação de papéis sobre o tema produção de energia elétrica através da energia nuclear, pois os depoimentos e os personagens de Cidade do Átomo são estereotipados, permitindo contrapor e discutir os diferentes ângulos pelos quais é abordada essa problemática.

\section{Conclusões}

Neste artigo buscamos mostrar que o jogo pode ser utilizado como importante estratégia didática no ensino de ciências. Procuramos mostrar a utilidade do jogo através 
das compreensões de Lloyd Rieber, um importante desenvolvedor de softwares educativos para o ensino de ciências, sobre o que ele chama de "jogo sério". Também, procuramos demonstrar como uma das estratégias de jogo, a de representação de papéis, pode ser usada na abordagem de temas científicos e tecnológicos polêmicos, tal como a produção de energia elétrica a partir de energia nuclear.

Nesse sentido, apresentamos dois programas envolvendo o tema radioatividade: o jogo de aventura Urânio 235, citando alguns equívocos conceituais que ele apresenta; e o software educativo Cidade do Átomo, indicando algumas características que ele possui e como pode apoiar o desenvolvimento de atividades de representação de papéis.

Por fim, como procuramos mostrar neste artigo, entendemos que a elaboração e o desenvolvimento das atividades de representação de papéis envolvem o protagonismo do professor. Dessa forma, procuramos incluir no software Cidade do Átomo personagens e cenários que possam ser utilizados para o desenvolvimento desse tipo de atividade. Pretende-se, posteriormente, verificar como esse tipo de atividade é efetivamente utilizada em contexto escolar.

\section{Referências:}

AMORY, A.; NAICKER, K.; VINCENT, J. \& ADAMS, C. The use of computer games as an educational tool. British Journal of Educational Technology, 30 (4), 311-321, 1999.

BLATNER, A. Role playing in education. Versão de 2002, disponível em: $<$ http://www.blatner.com/adam/pdntbk/rlplayedu.htm>. Acesso em: 18/03/2005.

BONNET, C. The relevance of role-playing in environmental education. Em: International Symposium BioEd, Paris, 12 -15 Maio de 2000. Disponível em: $<$ http://www.iubs.org/cbe/cbe_paper_index.html>. Acessado em: 18/03/2005.

CRONIN-JONES, L. Science scenarios: using role-playing to make science more meaningful. The Science Teacher, 67 (4), 48-52, 2000.

DUVEEN, J. \& SOLOMON, J. The great evolution trial: use of role-play in the classroom. Journal of Research in Science Teaching, 31 (5), 575-582, 1994.

EICHLER, M.L. \& DEL PINO, J.C. Carbópolis, um software para educação química. Química Nova na Escola, 11, 10-12, 2000.

EICHLER, M.L. \& DEL PINO, J.C. Popularização da ciência e mídia digital no ensino de química. Química Nova na Escola, 15, 24-26, 2002.

EICHLER, M.L.; GONÇALVES, M.R.; SILVA, F.O.M.; JUNGES, F. \& DEL PINO, J.C. Uma proposta para o desenho interdisciplinar de ambientes virtuais de aprendizagem de ciências. Revista Novas Tecnologias na Educação, 1 (2), 2003.

JACKSON, P.T. \& WALTERS, J.P. Role-playing in analytical chemistry: the alumni speak. Journal of Chemical Education, 77 (8), 1019-1024, 2000.

MAIER, H.W. Role playing: Structures and educcational objectives. Journal of Child and Youth Care, 6 (4): 145-150, 1991.

PAULA, J. (1996). Refletindo sobre o jogo. Motriz, 2 (2), 86 - 96.

PIAGET, J. A formação do símbolo na criança: imitação, jogo, sonho, imagem e representação. Rio de Janeiro: Zahar, 1975 (Trabalho originalmente publicado em 1945).

RIEBER, L.P., SMITH, L., \& NOAH, D. The value of serious play. Educational Technology, 38 (6), 29-37, 1998.

RIEBER, L.P. \& MATZKO, M.J. Serious design for serious play in physics. Educational Technology, 41 (1), 14-24, 2001.

RIEBER, L.P. Designing learning environments that excite serious play. Em: Annual Meeting of Australasian Society for Computers in Learning in Tertiary 
Education, Melbourne, Australia, 2001. Disponível em: < http://it.coe.uga.edu/ lrieber/>. Acesso em: 18/03/2005.

RIEBER, L.P. Seriously considering play: Designing interactive learning environments based on the blending of microworlds, simulations, and games. Educational Technology Research \& Development, 44 (2), 43-58, 1996.

ROMERO, E. (2005). S.T.A.L.K.E.R.: Shadow of Chernobyl - O mundo depois do acidente de Chernobyl. Terra Games. Disponível em: $<$ http://games.terra.com.br/analises/stalker.htm>. Acesso em: 18/03/2005.

SILVA, F.O M.; JUNGES, F.; EICHLER, M.L.; DEL PINO, J. C. Análise de softwares educativos para modelagem de ambientes virtuais de aprendizagem. Em: Livro de Resumos do IX Salão de Iniciação Científica da UFRGS, Porto Alegre, 1997, p. 371.

TRUMBORE, C.R. A role-playing exercise in general chemistry. Journal of Chemical Education, 51 (2), 117-118, 1974.

WHISNANT, D.M. A role-playing exercise using a computer simulation. Journal of Chemical Education, 69 (1), 42-43, 1992. 